\title{
EVALUATION OF PHYTOCHEMICAL CONSTITUENTS AND ANTIMICROBIAL PROPERTIES OF MANGIFERA INDICA L. LEAVES AGAINST URINARY TRACT INFECTION-CAUSING PATHOGENS
}

\author{
GYANRANJAN MAHALIK ${ }^{1}$, SABUJ SAHOO ${ }^{2}$, KUNJA BIHARI SATAPATHY ${ }^{1}$
}

${ }^{1}$ Post Graduate Department of Botany, Utkal University, Bhubaneswar - 751 004, Odisha, India. ${ }^{2}$ Post Graduate Department of Biotechnology, Utkal University, Bhubaneswar - 751 004, Odisha, India. Email: kbs_bot@rediffmail.com

Received: 08 April 2017, Revised and Accepted: 25 May 2017

\section{ABSTRACT}

Objective: The main aim of this study was to evaluate the presence of different active compounds and their concentrations in different extracts of Mangifera indica L. leaves which can reduce the incidence of pathogens causing urinary tract infections (UTIs).

Methods: Leaves of M. indica L. were extracted in petroleum ether, methanol, and ethanol solvents by Soxhlet apparatus and screened for presence of secondary metabolites, antibacterial, and antifungal activities (agar well diffusion methods). The antimicrobial efficacy of different extracts was tested against UTI-causing organisms such as Escherichia coli, Shigella flexneri, Salmonella typhimurium, Staphylococcus aureus, Pseudomonas aeruginosa, Klebsiella pneumoniae, Proteus mirabilis, Candida albicans, Candida krusei, and Candida tropicalis.

Results: Leaves of $M$. indica revealed the presence of carbohydrates, proteins, amino acid, saponins, phenolics, tannins, sterols, and glycosides. Methanolic and ethanolic extracts of $M$. indica actively showed the presence of all the phytochemical constituents. All the test bacterial strains were found sensitive to ethanolic and aqueous extracts of $M$. indica leaves while P. mirabilis, $K$. pneumoniae, and $S$. flexineri showed resistance to petroleum ether extracts. Aspergillus niger was resistant to all the extracts of $M$. indica leaves, whereas $C$. tropicalis, $C$. krusei, and $C$. albicans demonstrated sensitivity toward ethanolic extracts. Higher concentrations of methanolic and petroleum ether extracts were capable of inhibiting the growth of fungal strains such as $C$. albicans, $C$. tropicalis, and $C$. krusei, whereas $C$. tropicalis was sensitive to all the extracts.

Conclusion: The extracts of $M$. indica leaves can be used as herbal cure to treat UTIs caused by different microorganisms

Keywords: Antimicrobial, Phytochemical, Soxhlet, Urinary tract infection.

(c) 2017 The Authors. Published by Innovare Academic Sciences Pvt Ltd. This is an open access article under the CC BY license (http://creativecommons. org/licenses/by/4. 0/) DOI: http://dx.doi.org/10.22159/ajpcr.2017.v10i9.19034

\section{INTRODUCTION}

The issue of herbal medicine is fast growing around worldwide [1]. The medicinal effects of plant materials typically result from the combination of secondary metabolites present in the plant [2]. These chemical metabolites are grouped into primary and secondary metabolites (phytochemicals). Phytochemicals are good sources of medicinal drugs for which that with antimicrobial effects are used for the treatment of different microbial infections [3]. Mangifera indica L. belongs to angiospermic family Anacardiaceae and is widely used as a source of food, medicines, and timber. In Dhenkanal district of Odisha, the tribes commonly use different parts of $M$. indica such as leaf, bark, and flowers for herbal preparations in the treatment of various diseases such as urinary tract infections (UTIs), gastrointestinal disorders, toothache, dysentery, diarrhea, and respiratory tract infections [4]. Ethnobotanical survey carried out in the district has resulted in the documentation of a number of plants that are used in the treatment of urinary disorders including M. indica [4].

The present study aims at investigating the phytochemical constituents, antimicrobial activities of leaf extracts of $M$. indica using different solvents against the UTI-causing pathogens such as Escherichia coli, Shigella flexneri, Salmonella typhimurium, Staphylococcus aureus, Pseudomonas aeruginosa, Klebsiella pneumoniae, Proteus mirabilis, Candida albicans, Candida krusei, and Candida tropicalis.

\section{METHODS}

\section{Study area}

Dhenkanal is one of the centrally located districts in Odisha lying between Longitude $85^{\circ} 58^{\prime}$ to $86^{\circ} 20^{\prime}$ East and Latitude $20^{\circ} 29^{\prime}$ to $21^{\circ} 11^{\prime}$ North and bounded by the Keonjhar district at the North, Cuttack district at the South, Jajpur at the East, and Angul in the West (Fig. 1).
Plant material collection

M. indica L. leaves were collected from different forest pockets of Dhenkanal district. The plant was identified and authenticated by following "Flora of Orissa" [5] and voucher specimen number - 2215 was submitted to the herbarium of Utkal University, Odisha.

\section{Sample and extract preparation}

Freshly collected leaf samples were washed and air-dried under shade at room temperature for 7-10 days. After drying, the samples were chopped into small pieces, and the materials were grounded into powder form using mortar and pestle. Powdered samples were then stored in air tight containers for further use [6].

Powdered samples were successively extracted with different solvents such as petroleum ether, methanol, ethanol, and aqueous in Soxhlet apparatus and then the extracts were allowed to evaporate in a water bath. The dried extracts were dissolved in $10 \%$ dimethyl sulfoxide (DMSO) and stored in airtight container in a refrigerator [7].

\section{Phytochemical screening}

The initial phytocompound testing of the various solvent extracts was performed using standard protocol for determining the presence of carbohydrates, proteins, amino acid, saponins, phenolics, tannins, sterols, and glycosides [8-10]

\section{Test organisms}

The test bacterial cultures including E. coli, S. flexneri, S. typhimurium, $S$. aureus, $P$. aeruginosa, K. pneumoniae, and P. mirabilis were collected from IMTECH Chandigarh while test fungal cultures such as C. albicans, C. krusei and C. tropicalis were collected from SCB Medical College, Cuttack, Odisha. All the bacterial cultures were maintained in nutrient agar slants, and fungal cultures were maintained in potato dextrose 


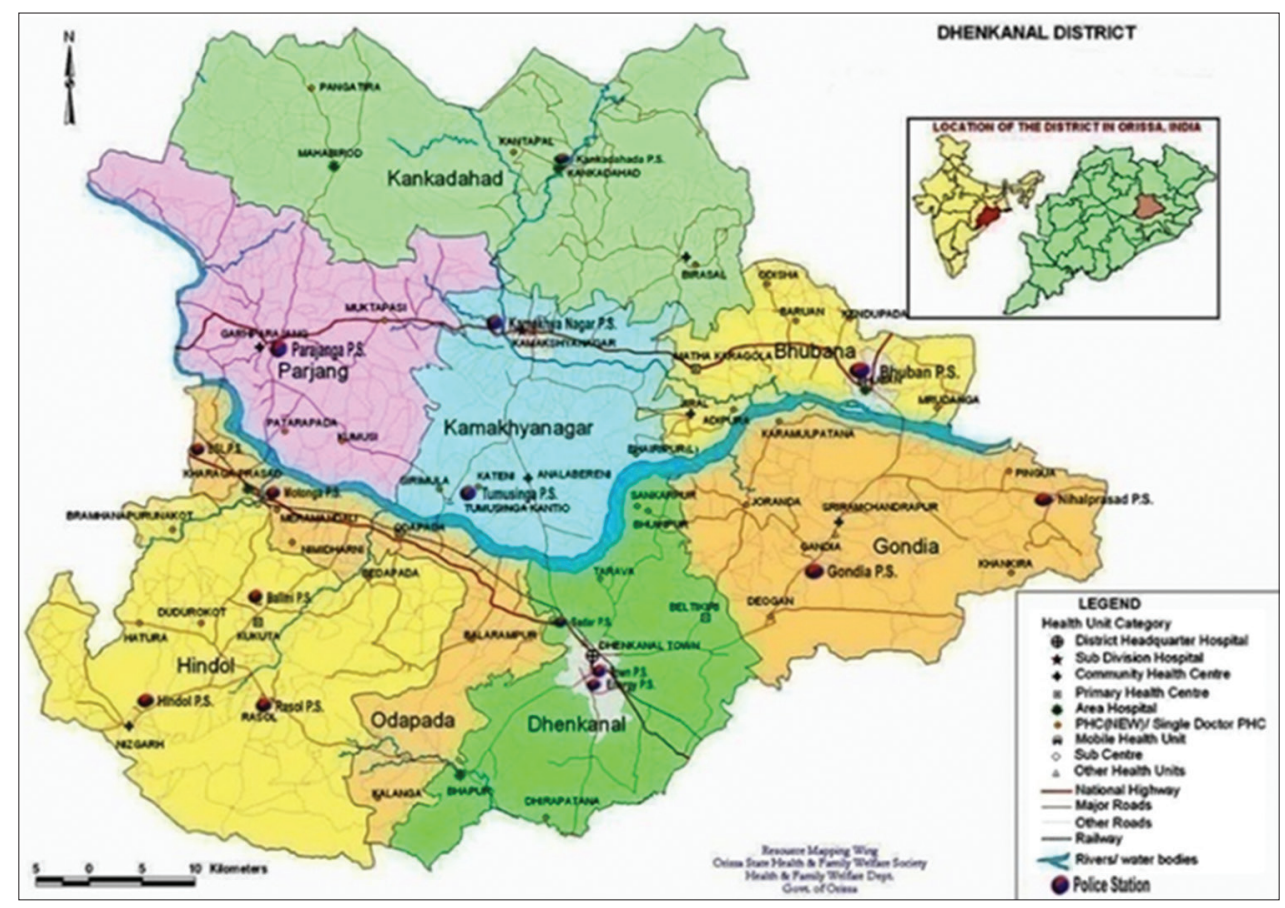

Fig. 1: Map of Dhenkanal district of Odisha

agar (PDA) slants which were kept in a refrigerator for further using during experimentation.

\section{Antibacterial and antifungal susceptibility assay}

A standardized concentration of inoculum with fixed volume is spread evenly on the surface of gelled agar plate. A hole of about $6 \mathrm{~mm}$ in diameter is punched with a sterile cork borer aseptically in plates. A fixed volume $(50 \mu \mathrm{l})$ of plant extract was then introduced into the bored agar well and incubated at optimum temperature (bacteria $-37^{\circ} \mathrm{C}$ for $24 \mathrm{hr}$ and fungi $-28^{\circ} \mathrm{C}$ for $72 \mathrm{hr}$ ) depending on the test microorganism $[11,12]$.

\section{Determination of minimum inhibitory concentration (MIC)}

The MIC of the crude extracts was determined by preparing fresh broth cultures of bacterial strains. Different concentrations of crude extracts $(50,100,200,400,600,800$, and $1000 \mu \mathrm{g} / \mathrm{ml})$ were prepared with DMSO and mixed with 24-hour-old bacterial inoculation and allowed to grow at $37^{\circ} \mathrm{C}$ for $24 \mathrm{hr}$. Turbidity due to bacterial growth was observed in each concentration at $620 \mathrm{~nm}$ [13].

A $1 \mathrm{ml}$ of different concentration of crude extracts $(50-1000 \mu \mathrm{g} / \mathrm{ml})$ was inoculated in plates swabbed with fungal cultures containing PDA and incubated for $72 \mathrm{hrs}$ at $28^{\circ} \mathrm{C}$. The least concentration was taken as MIC for fungal cultures [14]

\section{Statistical analysis}

All experimental results were statistically analyzed and expressed as a mean \pm standard deviation.

\section{RESULTS AND DISCUSSION}

\section{Phytochemical constituents}

The different extracts of $M$. indica leaves were found to contain different phytochemical constituents. The aqueous extract revealed presence of carbohydrates, proteins, amino acids, phenols, tannins, sterols, and saponins in low amounts, whereas the petroleum extracts were found to contain moderate amount of these phytocompounds besides high amounts of glycosides. Similarly, methanolic extracts contained all the said phytoconstituents, but some showed moderate concentrations and others resulted in high quantity of the compounds. In this extract, phenol, tannins, and glycosides were found in high quantity, whereas carbohydrates, proteins, amino acids and sterols were in moderate amounts. Proteins, amino acids, phenols, tannins, sterols, and glycosides were present in high amount in case of ethanolic extract of the plant. It was also observed that ethanolic extract contained moderate amount of carbohydrates and saponins, whereas both petroleum ether and methanolic extracts contained saponin in less quantity.

The phytoconstituents of different extracts are presented in Table 1. Phytoconstituents have been reported to inhibit bacteria and fungi [15]. It can be said that the phytochemicals in the leaf extracts of $M$. indica may be responsible for the antibacterial and antifungal activities against different UTI causing pathogens. Since these pathogens mostly cause UTIs, it can be expected that the extracts used in the present study can be utilized for reducing the incidence of disease.

\section{Antibacterial activity}

In the present study, the inhibitory effects of different extracts (petroleum ether, methanol, ethanol and aqueous) of $M$. indica L. leaves were evaluated against seven UTI causing bacterial strains such as E. coli, S. flexneri, S. typhimurium, S. aureus, P. aeruginosa, K. pneumoniae, and $P$. mirabilis. The data presented in Table 2 indicated the antimicrobial efficiency of different extracts.

Aqueous extracts showed highest inhibitory activity against $S$. typhi $(14.6 \mathrm{~mm}$ at $20 \mathrm{mg} / \mathrm{ml})$ and lowest against $S$. flexineri $(12 \mathrm{~mm}$ at $20 \mathrm{mg} / \mathrm{ml}$ ). The effectiveness of aqueous extracts against bacterial strains was as follows: S. typhi $>$ K. pneumoniae $>$ P. mirabilis $>$ E. coli $>$ S. aureus $>$ P. aeruginosa $>$ S. flexineri.

Petroleum extracts showed significant inhibition zone of $22 \mathrm{~mm}$ against $P$. aeruginosa and lowest of $0 \mathrm{~mm}$ against $S$. flexneri, $K$. pneumoniae, and P. mirabilis, respectively. S. flexneri, K. pneumoniae, and P. mirabilis were found resistant to petroleum ether extracts. The effectiveness of petroleum ether extracts were as follows: P. aeruginosa $>$ E. coli $>$ S. typhimurium $>$ S. aureus $>$ S. flexineri $=$ K. pneumoniae $=$ P. mirabilis .

Methanolic extracts were effective against the pathogens such as S. typhimurium $>$ P. aeruginosa $>$ P. mirabilis $>S$. flexineri $>$ E. coli $>$ $S$. aureus $>$ K. pneumoniae. S. typhimurium showed maximum inhibition of $20.4 \mathrm{~mm}$ at $20 \mathrm{mg} / \mathrm{ml}$ and K. pneumoniae showed inhibition zone of $11.6 \mathrm{~mm}$. 
Table 1: Phytochemical analysis of $M$. indica leaf extracts

\begin{tabular}{lllll}
\hline Sl. No. & Phytochemical constituents & Aqueous & Petroleum ether & Methanol \\
\hline 1 & Carbohydrates & + & - & ++ \\
2 & Proteins and amino acid & + & ++ & ++ \\
3 & Phenols and tannins & + & ++ & ++ \\
4 & Sterols & + & + & ++ \\
5 & Glycosides & - & ++ & ++ \\
6 & Saponins & + & + & ++ \\
++++ & ++ \\
\hline
\end{tabular}

(+): Present; (++): Moderately present; (+++): Highly present; (-): Absent. M. indica: Mangifera indica

Table 2: Antibacterial activities of different extracts of $M$. indica L. leaves against UTI-causing bacterial strains

\begin{tabular}{|c|c|c|c|c|c|c|}
\hline \multirow[t]{2}{*}{ Bacterial strains } & \multirow[t]{2}{*}{ Extracts } & \multicolumn{4}{|c|}{ Zone of inhibition (mm) } & \multirow{2}{*}{$\begin{array}{l}\text { Ciprofloxacin } \\
0.1 \mathrm{mg} / \mathrm{ml}\end{array}$} \\
\hline & & $5 \mathrm{mg} / \mathrm{ml}$ & $10 \mathrm{mg} / \mathrm{ml}$ & $15 \mathrm{mg} / \mathrm{ml}$ & $20 \mathrm{mg} / \mathrm{ml}$ & \\
\hline \multirow[t]{4}{*}{ E. coli } & Aqueous & $10.2 \pm 0.41$ & $10.8 \pm 0.41$ & $11.4 \pm 0.81$ & $13.3 \pm 0.63$ & \multirow[t]{4}{*}{$17.4 \pm 1.02$} \\
\hline & Pet. ether & $17.2 \pm 0.42$ & $17.2 \pm 0.75$ & $19.1 \pm 0.63$ & $19.4 \pm 0.81$ & \\
\hline & Methanol & $11.8 \pm 0.74$ & $13.8 \pm 0.74$ & $16.2 \pm 0.43$ & $16.2 \pm 0.41$ & \\
\hline & Ethanol & $11.4 \pm 0.49$ & $12.8 \pm 0.41$ & $15.1 \pm 0.63$ & $18.6 \pm 0.49$ & \\
\hline \multirow[t]{4}{*}{ S. flexneri } & Aqueous & $10.4 \pm 0.49$ & $11.1 \pm 0.63$ & $11.2 \pm 0.74$ & $12.3 \pm 0.63$ & \multirow[t]{4}{*}{$26.1 \pm 0.63$} \\
\hline & Pet. ether & - & - & - & - & \\
\hline & Methanol & $10.8 \pm 0.75$ & $13.6 \pm 0.81$ & $16.2 \pm 0.75$ & $17.2 \pm 0.75$ & \\
\hline & Ethanol & $11.4 \pm 0.48$ & $13.4 \pm 0.43$ & $16.4 \pm 0.49$ & $18.1 \pm 0.63$ & \\
\hline \multirow[t]{4}{*}{ S. typhimurium } & Aqueous & $10.2 \pm 0.41$ & $11.6 \pm 1.02$ & $13.2 \pm 0.98$ & $14.6 \pm 0.49$ & \multirow[t]{4}{*}{$25.8 \pm 0.75$} \\
\hline & Pet. ether & - & $15.2 \pm 0.75$ & $16.2 \pm 0.63$ & $18.1 \pm 0.63$ & \\
\hline & Methanol & $11.8 \pm 0.79$ & $14.6 \pm 0.82$ & $16.2 \pm 0.75$ & $20.4 \pm 0.75$ & \\
\hline & Ethanol & $12.1 \pm 0.63$ & $13.6 \pm 1.01$ & $15.2 \pm 0.74$ & $16.6 \pm 0.82$ & \\
\hline \multirow[t]{3}{*}{ S. aureus } & Aqueous & $10.6 \pm 0.81$ & $10.6 \pm 0.49$ & $12.6 \pm 0.81$ & $12.8 \pm 0.43$ & \multirow[t]{3}{*}{$26.3 \pm 0.63$} \\
\hline & Pet. ether & $12.2 \pm 0.89$ & $15.2 \pm 0.42$ & $16.4 \pm 0.49$ & $17.8 \pm 0.98$ & \\
\hline & Methanol & $13.2 \pm 0.43$ & $13.2 \pm 0.43$ & $13.6 \pm 0.49$ & $14.4 \pm 0.49$ & \\
\hline \multirow[t]{4}{*}{ P. aeruginosa } & Aqueous & $10.4 \pm 0.49$ & $11.2 \pm 0.41$ & $11.4 \pm 1.21$ & $12.2 \pm 0.74$ & \multirow[t]{4}{*}{$27.2 \pm 0.42$} \\
\hline & Pet. ether & $12.1 \pm 0.63$ & $17.4 \pm 0.82$ & $19.2 \pm 0.75$ & $22.1 \pm 0.89$ & \\
\hline & Methanol & $12.1 \pm 0.89$ & $13.6 \pm 0.49$ & $16.6 \pm 0.75$ & $18.2 \pm 0.75$ & \\
\hline & Ethanol & $10.4 \pm 0.48$ & $10.6 \pm 0.49$ & $11.3 \pm 0.89$ & $18.4 \pm 0.81$ & \\
\hline \multirow[t]{4}{*}{ K. pneumoniae } & Aqueous & $10.4 \pm 0.49$ & $11.1 \pm 0.63$ & $12.4 \pm 0.83$ & $13.6 \pm 1.02$ & \\
\hline & Pet. ether & - & - & - & - & \multirow{3}{*}{$23.6 \pm 0.8$} \\
\hline & Methanol & - & - & $10.4 \pm 0.49$ & $11.6 \pm 0.84$ & \\
\hline & Ethanol & $10.2 \pm 0.41$ & $11.4 \pm 0.48$ & $12.2 \pm 0.42$ & $12.6 \pm 0.81$ & \\
\hline \multirow[t]{4}{*}{ P. mirabilis } & Aqueous & $10.4 \pm 0.49$ & $11.6 \pm 0.49$ & $12.2 \pm 0.43$ & $13.4 \pm 0.49$ & \multirow[t]{4}{*}{$25.8 \pm 0.74$} \\
\hline & Pet. ether & - & - & - & - & \\
\hline & Methanol & $10.6 \pm 0.49$ & $14.4 \pm 0.49$ & $15.2 \pm 0.41$ & $17.6 \pm 0.49$ & \\
\hline & Ethanol & $12.2 \pm 0.41$ & $13.4 \pm 0.49$ & $15.4 \pm 0.49$ & $20.2 \pm 0.89$ & \\
\hline
\end{tabular}

*Values in the table are mean \pm SD of 5 replicates; (-) indicates no activity. M. indica: Mangifera indica, E. coli: Escherichia coli, S. flexneri: Shigella flexneri,

S. typhimurium: Salmonella typhimurium, S. aureus: Staphylococcus aureus, P. aeruginosa: Pseudomonas aeruginosa, K. pneumoniae: Klebsiella pneumoniae, P. mirabilis:

Proteus mirabilis, SD: Standard deviation

Ethanolic extracts of $M$. indica effectively inhibited $P$. mirabilis showing $20 \mathrm{~mm}$ inhibition zone and showed less activity against K. pneumoniae exhibiting $12.6 \mathrm{~mm}$ zone of inhibition. The sequence of inhibition was as follows: P. mirabilis $>$ E. coli $>$ P. aeruginosa $>$ S. flexineri $>$ S. typhimurium $>$ S. aureus $>$ K. pneumoniae.

Antibiotic ciprofloxacin at $0.1 \mathrm{mg} / \mathrm{ml}$ inhibited the test microbes in the sequence $P$. aeruginosa $(27.2 \mathrm{~mm})>S$. flexineri $(26 \mathrm{~mm})=S$. aureus $(26 \mathrm{~mm})>$ P. mirabilis $(25.8 \mathrm{~mm})=S$. typhimurium $(25.8 \mathrm{~mm})>$ K. pneumonia $(23.6 \mathrm{~mm})>$ E. coli $(17.4 \mathrm{~mm})$.

It is apparent that UTI-causing bacterial pathogens can be inhibited using different extracts of $M$. indica leaves. The leaves of the plant had demonstrated the potential to inhibit almost all the test bacterial strains in the present study. The effectiveness of the extracts might be due to the presence of certain phytochemical compounds that played a vital role in inhibiting UTI-causing pathogens. The antibiotic (ciprofloxacin) also showed inhibitory effect against tested bacterial pathogens but the regular use of antibiotic may lead to resistance to certain pathogens. Therefore, it can be suggested that the use of herbal formulation of the plant being cost-effective and free of side effects can be utilized as an alternative to antibiotics against UTI-causing pathogens.

\section{Antifungal activity}

Fungal strains in this investigation were more significantly controlled by ethanolic extracts of $M$. indica leaves followed by methanol and petroleum ether (Fig. 2a-d). The mycelial growth of $C$. albicans showed maximum inhibition with petroleum ether extracts up to $14.5 \mathrm{~mm}$ at $20 \mathrm{mg} / \mathrm{ml}$ followed by ethanolic extracts, i.e., $14.2 \mathrm{~mm}$ at $20 \mathrm{mg} / \mathrm{ml}$ and $14 \mathrm{~mm}$ with methanolic extracts but did not show any inhibitory effect with the aqueous extracts. Ethanolic extracts inhibited the fungus from $5 \mathrm{mg} / \mathrm{ml}$, but at $5 \mathrm{mg} / \mathrm{ml}$, no other extracts inhibited the growth of the test fungi even at $5 \mathrm{mg} / \mathrm{ml}$ concentration of the extract while other extracts inhibited $C$. albicans. Fluconazole showed the highest inhibition zone of $28.6 \mathrm{~mm}$ at $0.5 \mathrm{mg} / \mathrm{ml}$.

C. krusei showed maximum inhibition $(17.2 \mathrm{~mm})$ with ethanol extracts at $20 \mathrm{mg} / \mathrm{ml}$ followed by petroleum ether extracts $(13.6 \mathrm{~mm})$ and methanolic extracts (13.4 $\mathrm{mm}$ ) but did not show any inhibitory effect with petroleum ether extracts (at 5-15 mg/ml) and methanolic extracts (at $5 \mathrm{mg} / \mathrm{ml}$ ). Aqueous extracts inhibited the fungus from 5 to $20 \mathrm{mg} / \mathrm{ml}$ concentration while $20 \mathrm{mg} / \mathrm{ml}$ could inhibit the growth up to $13.6 \mathrm{~mm}$. Ethanolic extracts were found effective against $C$. krusei. Fluconazole at $0.5 \mathrm{mg} / \mathrm{ml}$ showed $12.8 \mathrm{~mm}$ inhibition. 


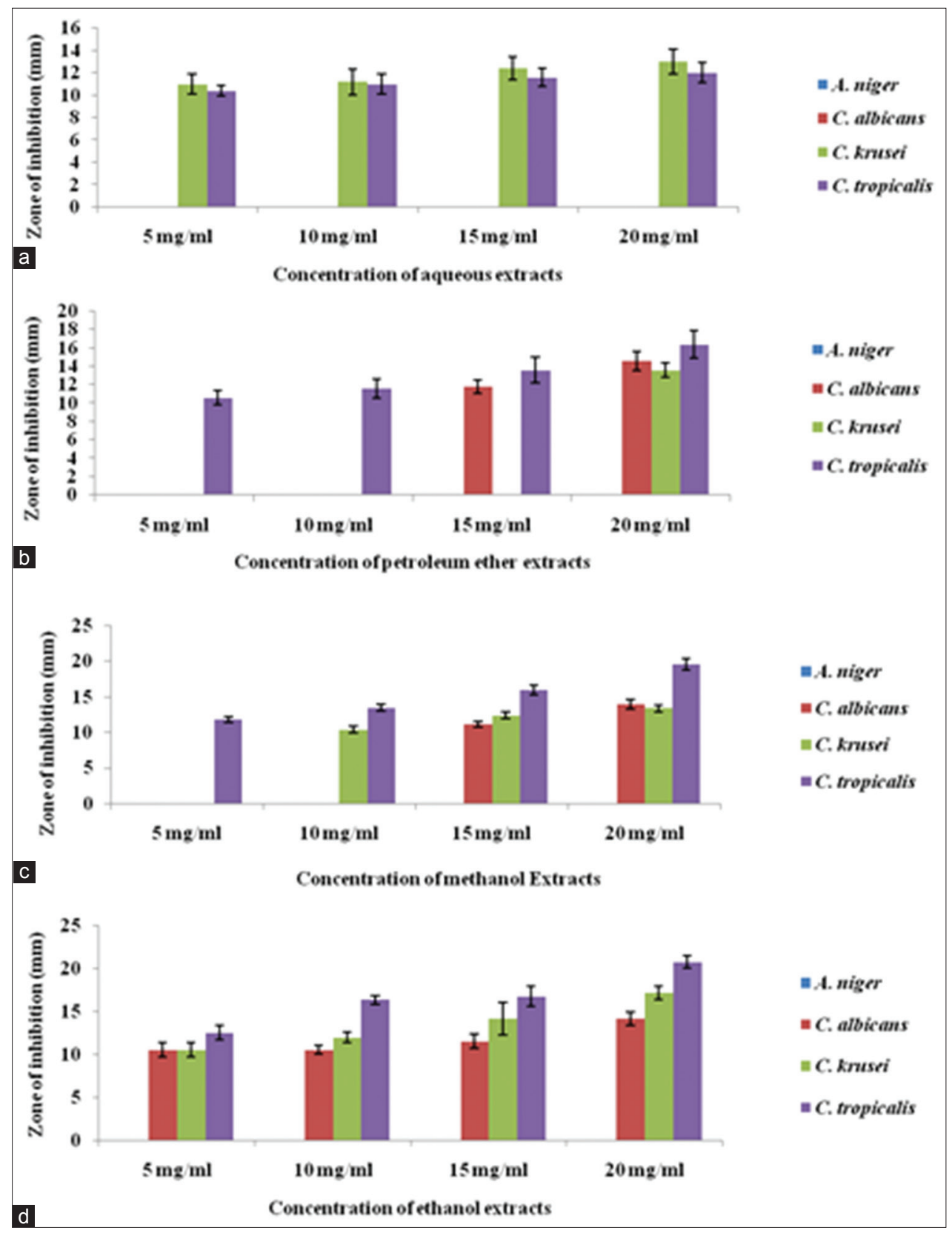

Fig. 2: (a) Effect of different concentration of aqueous extract of Mangifera indica leaves against urinary tract infection (UTI)-causing fungal strains. (b) Effect of different concentration of petroleum ether extract of $M$. indica leaves against UTI-causing fungal strains. (c) Effect of different concentration of methanol extract of $M$. indica leaves against UTI-causing fungal strains. (d) Effect of different concentration of methanol extract of $M$. indica leaves against UTI-causing fungal strains

The growth of $C$. tropicalis was found severely inhibited by ethanolic extracts followed by methanol, petroleum ether, and least by aqueous extracts. At $20 \mathrm{mg} / \mathrm{ml}$, ethanol extracts showed maximum inhibition of $20.8 \mathrm{~mm}$ while methanol extract exhibited $19.6 \mathrm{~mm}$ inhibition zone followed by petroleum ether $(16.4 \mathrm{~mm})$ and aqueous extract $(12 \mathrm{~mm})$. Fluconazole at $0.5 \mathrm{mg} / \mathrm{ml}$ showed inhibition of $15 \mathrm{~mm}$ diameter.

Aspergillus niger was found resistant to all the extracts along with fluconazole and did not demonstrate any inhibition zone.

Fungal pathogens are responsible for causing severe infectious diseases. Once it caused infections, it becomes difficult to be cured. Therefore, it is very important to maintain proper hygiene so as to avoid the fungal infections. Fluconazole inhibited all test fungal strains but could not inhibit $A$. niger. In this context, it can be said that A. niger was resistant to the above said antifungal compound. Other extracts (petroleum ether, methanol, and ethanol) efficiently inhibited all the three species of Candida but was poor in inhibiting the growth of A. niger, which was observed to be resistant and requiring new formulations and methods for its control.

MIC of bacterial and fungal pathogens

There was remarkable difference in MIC values of the crude extract of all the four leaf extracts of $M$. indica to the selected bacterial and fungal pathogenic strains. Bacterial strain such as K. pneumoniae showed resistance to all the extracts of $M$. indica leaves while $S$. typhimurium, $S$. flexneri, $K$. pneumoniae, and P. mirabilis showed resistance to petroleum ether extract (Table 3 ) and E. coli exhibited sensitivity at $600-1000 \mu \mathrm{g} / \mathrm{ml}$ concentration of the extract. All bacterial strains except $E$. coli and $K$. pneumoniae showed the highest sensitivity to ciprofloxacin at $100 \mu \mathrm{g} / \mathrm{ml}$. 
Table 3: MIC of different extracts of $M$. indica leaves against bacterial and fungal human pathogens causing UTI

\begin{tabular}{|c|c|c|c|c|c|}
\hline \multicolumn{5}{|l|}{$\operatorname{MIC}(\mu \mathrm{g} / \mathrm{ml})$} & \multirow[t]{2}{*}{ Ciprofloxacin } \\
\hline Bacteria & Aqueous & Pet. ether & Methanol & Ethanol & \\
\hline E. coli & 1000 & 600 & 800 & 1000 & 600 \\
\hline S. flexneri & 1000 & - & 1000 & 1000 & 100 \\
\hline S. typhimurium & - & - & 800 & 800 & 100 \\
\hline S. aureus & 1000 & 1000 & 800 & 800 & 100 \\
\hline P. aeruginosa & - & 1000 & 1000 & 1000 & 100 \\
\hline K. pneumoniae & - & - & - & - & 200 \\
\hline P. mirabilis & - & - & 1000 & 1000 & 100 \\
\hline Fungus & Aqueous & Pet. ether & Methanol & Ethanol & Fluconazole \\
\hline A. niger & - & - & - & - & - \\
\hline C. albicans & - & - & - & - & 100 \\
\hline C. krusei & - & - & - & 1000 & 800 \\
\hline C. tropicalis & 1000 & 1000 & 1000 & 1000 & 600 \\
\hline
\end{tabular}

UTI: Urinary tract infection, M. indica: Mangifera indica, E. coli: Escherichia coli, S. flexneri: Shigella flexneri, S. typhimurium: Salmonella typhimurium,

S. aureus: Staphylococcus aureus, P. aeruginosa: Pseudomonas aeruginosa, K. pneumoniae: Klebsiella pneumoniae, P. mirabilis: Proteus mirabilis, A. niger: Aspergillus niger,

C. albicans: Candida albicans, C. krusei: Candida krusei, C. tropicalis: Candida tropicalis

I was observed that fungal strains were less sensitive to the extracts of $M$. indica than bacterial strains. The growth of fungal strains was sensitive to chemical compound like fluconazole varying from 600 to $1000 \mu \mathrm{g} / \mathrm{ml}$ except $A$. niger which was resistant to fluconazole as well as all the concentration of different plant extracts. All the four extracts were found to be effective against $C$. tropicalis ranging concentration of $600-1000 \mu \mathrm{g} / \mathrm{ml}$ (Table 3). However, C. krusei was sensitive to ethanolic extract of $M$. indica at $1000 \mu \mathrm{g} / \mathrm{ml}$.

\section{CONCLUSION}

The herbal therapy is efficient in controlling different bacterial and fungal infections. The leaves of $M$. indica were subjected to many extraction systems such as aqueous, petroleum ether, methanol, and ethanol. All the extracts were found effective in inhibiting growth of bacterial as well as fungal strains causing UTI. Although antibiotic and antifungal agents are capable of inhibiting or lowering the incidence of UTI, it also lead to several resistance mechanisms in bacterial and fungal strains and the pathogens may further become resistant to those antimicrobial drugs. Later the pathogens may change their structures or may convert to more virulent or pathogenic form leading to severe infections. To avoid costly antibiotics, nowadays, herbal therapy is being used due to its wide range of applications and no side effects. The phytochemical constituents are the secondary metabolites present in medicinal plants that provide defense against pathogenic strains of UTI and other infections. It may be concluded that the effectiveness of $M$. indica leaves may be due to the presence of secondary metabolites for which it can be suggested that the extracts of $M$. indica leaves can be used as herbal cure to treat UTIs caused by different pathogens.

\section{ACKNOWLEDGMENT}

The authors are thankful to the Head, Post Graduate Department of Botany, Utkal University, Bhubaneswar, Odisha for providing necessary laboratory facilities to conduct the study. The financial assistance received from the University Grants Commission, Government of India, New Delhi in the form of RGNF fellowship to the first author is deeply acknowledged.

\section{REFERENCES}

1. Amaechi I. Natural medicine potentials. Pharmaceutical society of Nigeria (PNS) Conference Proceedings, Abuja; 2003.

2. Ayodele QS. The effect of herbal remedies. Daily Champion 2003;???????

3. Kurian S, Josekumar VS. Phytochemical screening, antimicrobial activity and brine shrimp lethality bioassay of different extracts of Alysicarpus vaginalis Var. Nummularifolius (DC.) MIQ. (Family: Fabaceae). Int J Pharm Pharm Sci 2017;9(1):1.

4. Mahalik G, Satapathy KB, Sahoo S. Ethnobotanical survey of plants used in treatment of urinary disorders in Dhenkanal district of Odisha, India. J Environ Sci Toxicol Food Technol 2015;9(8):58-63.

5. Saxena HO, Brahmam M. Flora of Orissa. Vol. 1-4. Orissa: Orissa Forest Development Corporation; 1994-1996.

6. Tetyana P, Prozesky EA, Jager AK. Some medicinal properties of Cussonia and Schefflera species used in traditional medicine. S Afr J Bot 2002;68(1):51-4.

7. Nair R, Kalariya T, Chanda S. Antibacterial activity of some selected Indian medicinal flora. Turk J Biol 2005;29(1):41-7.

8. Sinha S, Raghuwanshi R. Phytochemical screening and antioxidant potential of Eclipta prostrata (L) l-a valuable herb. Int J Pharm Pharm Sci 2016;8(3):255-60.

9. Dixit A, Rohilla A, Dixit J, Singh V. Qualitative analysis of various plant extracts of Alpinia officinarum. Int J Pharm Chem Biol Sci 2014;4(3):505-8

10. Soares MO, Alves RC, Pires PC, Oliveira MB, Vinha AF. Angolan Cymbopogon citratus used for therapeutic benefits: Nutritional composition and influence of solvents in phytochemicals content and antioxidant activity of leaf extracts. Food Chem Toxicol 2013;60:413-8.

11. Mbata TI, Debiao LU, Saikia A. Antibacterial activity of the crude extract of Chinese green tea (Camellia sinensis) on Listeria monocytogenes. Afr J Biotechnol 2006;7:1571-3.

12. Norrell SA, Messley KE. Microbiology Laboratory Manual: Principles and Applications. New Jersey: Prentice-Hall; 1997.

13. Cowan MM. Plant products as antimicrobial agents. Clin Microbiol Rev 1999;12(4):564-82.

14. Nascimento GG, Locatelli J, Freitas PC, Silva GL. Antibacterial activity of plant extracts and phytochemicals on antibiotic-resistant bacteria. Braz J Microbiol 2000;31(4):886-91.

15. Doughari JH, El-Mahmood AM, Tyoyina I. Antimicrobial activity of leaf extracts of Senna obtusifolia L. Afr J Pharm Pharmacol 2008;2(1):7-13. 